\title{
Brain sex differences: the androgynous brain is advantageous for mental health and well-being
}

\author{
Qiang Luo ${ }^{1,2}$ and Barbara J. Sahakian (iD) $1,3,4$ 网 \\ (c) The Author(s) 2021, corrected publication 2021
}

Neuropsychopharmacology (2022) 47:407-408; https://doi.org/10.1038/s41386-021-01141-z

Studies of personality and sex differences have reported that male's and female's basic personality traits appear to differ on average, in several respects [1]. From a psychological perspective, these sex differences are thought to result from perceived gender roles, gender socialisation and socio-structural power differentials, although the evolutionary theory has also been used to explain these differences [1]. However, psychological studies have already suggested that people can be androgynous, having mixed personality traits that are stereotypically considered to be male or female [2]. Furthermore, most of us are in fact probably somewhere on a spectrum between what we stereotypically consider a male or a female [2].

Importantly, such 'psychological androgyny' has long been associated with traits such as better cognitive flexibility (the mental ability to shift between different tasks or thoughts), social competence, mental health [3] and emotional reactivity [4]. For example, extreme masculine norms are detrimental, as evidenced by a meta-analysis showing that conformity to these norms incurs social costs and psychiatric symptoms, including depression, loneliness and substance abuse [5]. In addition, considering DSM-5 diagnoses, autism spectrum disorder, attention-deficit/hyperactivity disorder and conduct disorder are more commonly diagnosed in males, whereas eating disorders, major depressive disorder and generalised anxiety disorder are more commonly diagnosed in females [6]. But how does this relate to the brain? Is there such a thing as 'brain androgyny'? While male and female brains are similar, the connectivity between brain areas has been shown to differ [3]. We used these connectivity markers to characterise the brains of 9620 participants (4495 male and 5125 female). Indeed, our findings suggest that brain androgyny does exist [3]. Using the sex differences of the resting-state functional connectivity we built a multivariate classifier to estimate the likelihood of a given functional brain network to represent a male brain and achieved $77.75 \%$ classification accuracy when the model was applied to an independent dataset. Instead of binarizing the output of this classifier, we created a brain continuum, with male and female at the extreme ends, using the continuous output of this classifier. Indeed, we found that participants who mapped at the centre of this continuum, representing androgyny, had fewer mental health symptoms, such as depression and anxiety, compared with those at the two extreme ends. These findings support our novel hypothesis that there exists a neuroimaging concept of brain androgyny, which may be associated with better mental health in a similar way to psychological androgyny. The complex interaction of biological, psychological and environmental factors and how they modulate brain function requires further understanding. Future research on these topics is needed to progress understanding as well as to elucidate the influences on brain androgyny across the life span. Given that we have found that an androgynous brain offers better mental health, it follows that, for optimal performance in school and work, and for better wellbeing throughout life, we need to avoid extreme stereotypes and offer children and adolescents opportunities not restricted by their biological sex as they grow up.

\section{REFERENCES}

1. Schmitt DP, Long AE, McPhearson A, O'Brien K, Remmert B, Shah SH. Personality and gender differences in global perspective. Int J Psychol. 2017;52(S1):45-56.

2. Reis HT, Carothers BJ. Black and white or shades of gray: are gender differences categorical or dimensional? Curr Directions Psychological Sci. 2014;23:19-26.

3. Zhang Y, Luo Q, Huang C, Lo C, Langley $C$, Desrivières $S$, et al. The human brain is best described as being on a female/male continuum: evidence from a neuroimaging connectivity study. Cereb Cortex. 2021;31:3021-33.

4. Yu K, Liao Y, Fu D, Chen S, Long Q, Xu P, et al. Androgyny eliminates sex differences in emotional reactivity: ERP and network coupling evidences. Neurosci Lett. 2020;720:134776.

5. Wong YJ, Ho MH, Wang SY, Miller IS. Meta-analyses of the relationship between conformity to masculine norms and mental health-related outcomes. J Counseling Psychol. 2017;64:80.

6. Hines M. Neuroscience and sex/gender: looking back and forward. J Neurosci. 2020;40:37-43.

\section{AUTHOR CONTRIBUTIONS}

$\mathrm{QL}$ and BJS contributed equally.

\section{FUNDING INFORMATION}

Dr. Luo was supported by the National Key Research and Development Program of China (grant 2019YFA0709502), the National Natural Science Foundation of China (grant 81873909), the Shanghai Committee of Science and Technology (20ZR1404900), the Shanghai Municipal Science and Technology Major Project (grant 2018SHZDZX01 and grant 2021SHZDZX0103). Professor Sahakian's research is conducted within the NIHR MedTech and In vitro diagnostic Co-operative (MIC) and the NIHR Cambridge Biomedical Research Centre (BRC) Mental Health and Neurodegeneration Themes.

\footnotetext{
${ }^{1}$ Institute of Science and Technology for Brain-Inspired Intelligence, Ministry of Education-Key Laboratory of Computational Neuroscience and Brain-Inspired Intelligence, Fudan

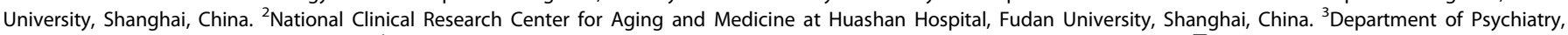
University of Cambridge, Cambridge, UK. ${ }^{4}$ Behavioural and Clinical Neuroscience Institute, University of Cambridge, Cambridge, UK. ${ }^{凶}$ email: bjs1001@cam.ac.uk
} 


\section{COMPETING INTERESTS}

Professor Sahakian has served as a consultant for Cambridge Cognition and Greenfield BioVentures. Dr. Luo reports no financial relationships with commercial interests.

\section{ADDITIONAL INFORMATION}

Correspondence and requests for materials should be addressed to B.J.S.

Reprints and permission information is available at http://www.nature.com/ reprints

Publisher's note Springer Nature remains neutral with regard to jurisdictional claims in published maps and institutional affiliations. (c) Open Access This article is licensed under a Creative Commons Attribution 4.0 International License, which permits use, sharing, adaptation, distribution and reproduction in any medium or format, as long as you give appropriate credit to the original author(s) and the source, provide a link to the Creative Commons license, and indicate if changes were made. The images or other third party material in this article are included in the article's Creative Commons license, unless indicated otherwise in a credit line to the material. If material is not included in the article's Creative Commons license and your intended use is not permitted by statutory regulation or exceeds the permitted use, you will need to obtain permission directly from the copyright holder. To view a copy of this license, visit http://creativecommons. org/licenses/by/4.0/.

(c) The Author(s) 2021, corrected publication 2021 